\title{
Correction to: Development of the St. Benedict Paul Trap at the Nuclear Science Laboratory
}

\section{Daniel Burdette ${ }^{1} \cdot$ Maxime Brodeur $^{1} \cdot$ Patrick O'Malley $^{1} \cdot$ Adrian Valverde $^{1}$}

Published online: 20 August 2019

(C) Springer Nature Switzerland AG 2019

\section{Correction to: Hyperfine Interact (2019) 240:70 https://doi.org/10.1007/s10751-019-1606-7}

The original version of this article was revised because this article was published with five instances of the word neutrino spelled out in math mode (\$\neutrino\$ in text) which should be the symbol nu (\$lnu\$).

Publisher's note Springer Nature remains neutral with regard to jurisdictional claims in published maps and institutional affiliations.

This article is part of the Topical Collection on Proceedings of the 7th International Conference on Trapped Charged Particles and Fundamental Physics (TCP 2018), Traverse City, Michigan, USA, 30 September-5 October 2018

Edited by Ryan Ringle, Stefan Schwarz, Alain Lapierre, Oscar Naviliat-Cuncic, Jaideep Singh and Georg Bollen The online version of the original article can be found at https://oi.org/10.1007/s10751-019-1606-7

Daniel Burdette

dburdett@nd.edu

1 Department of Physics, University of Notre Dame, Notre Dame, IN 46556, USA 